\title{
What Would Have Happened To Humanity If Steve Jobs Was Aborted?
}

\author{
A Commentary
}

\author{
Hani Raoul Khouzam,MD;MPH. ${ }^{1,2 *}$ \\ ${ }^{1}$ Monterey County Health Salinas Department Adult Services, Behavioral Health Bureau, USA \\ ${ }^{2}$ Staff Psychiatrist, Natividad Medical Center Salinas, USA
}

*Corresponding author: Hani Raoul Khouzam, 1Monterey County Health Salinas Department Adult Services, Behavioral Health Bureau, USA.

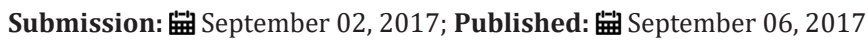

If unborn children are not human beings that are worthy of compassion and love, then abortion would be absolutely justified as a medically safe and legal procedure that get rid of a bundle of unwanted tissues and the bearers of these unwanted tissues should maintain their full autonomy in getting rid of them. However, if the unborn is a human being, then there will be no adequate moral justification for abortion. In the textbook "The Developing Human: Clinically Oriented Embryology" which is taught in most US medical schools, the authors Keith L. Moore, T. V. N. Persaud and Mark G. Torchia assert the scientific fact that "Human development begins at fertilization". The process during which a male gamete or sperm (spermatozoo development) unites with a female gamete or oocyte (ovum) to form a single cell called a zygote. This highly specialized, totipotent cell marked the beginning of each of us as a unique individual (embryo). So only the embryo possesses this self-directed inherent capacity for all human development. As a consequence, the inherent capacity for all human function lies within the embryo's whole human entity.

Pro- life supporters have persistently supported and advocated the notion that elective abortion is an irreversible procedure that lead to the termination of an unborn child and they also have argued that if mothers who refused to abort had succumbed to the pressure of getting rid of an unwanted pregnancy several individuals who have made a positive impact on humanity would have not been born. Among the individuals that are frequently mentioned as being saved from being aborted as children because of their mother refusal to undergo this procedure have included Pope John Paul II's mother's who was advised to have an abortion after losing her daughter who died shortly after birth, Andrea Bocelli's mother who was also advised to have an abortion after she was misdiagnosed with appendicitis during her pregnancy, the actor Jack Nicholson, singers Celine Dion and Justin Bieber, the National Football League player Tim Tebow and lastly but not last Steve Jobs the entrepreneur, businessman, inventor, and industrial designer.
In addition to being the chairman, and the chief executive officer, and a co-founder of Apple he mentioned in his autobiography that he "Was Glad He Didn't Become a Victim of Abortion".

Pro- choice supporters on the other hand debunk the pro -life assumption about humanity's significant losses from the "would be genius" if their mothers chose to abort them because they were the product of an unwanted pregnancy. Using the same assumption they argue what would have happened to humanity if Hitler, Stalin or North Korea's leader Kim Jong-un were aborted?

Human life does not come from the father or the mother of an unborn child. It is given by the Creator and not by ourselves. It is not earned on the basis of genius or amazing achievement and it cannot be relinquished by reason of human failures. Although humanity often forfeit its dignity by pursuing selfish aspirations and destructive ambitions, yet despite all the pain and suffering that are inflicted on humanity by the deviant behaviors of some, the status of the created humans as bearers of God's image Imago Dei still confirm their status as possessors of great value. The termination of an unwanted pregnancy through abortion is a destruction of the life of an innocent unborn child. It highlights how far humanity has failed to live up to the God given human dignity.

The purpose of this commentary is to clarify that all human life is special and of great value. Each person is made in the image of God and as such is unique, sacred and wonderfully created, irrespective of potential future accomplishments, successes or failures. This commentary is based on the personal belief and a conviction of its author and does not reflect the official point of view of any affiliated organization or employing entity.

\section{Acknowledgement}

To my family, friends and colleagues for their support, encouragement and inspirations. 